\title{
Remote Ischemic Pre-Conditioning Alleviates Contrast- Induced Acute Kidney Injury in Patients With Moderate Chronic Kidney Disease
}

\author{
Gen Igarashi, MD; Kenji Iino, MD; Hiroyuki Watanabe, MD; Hiroshi Ito, MD
}

\begin{abstract}
Background: Although remote ischemic preconditioning (RIPC) is shown to preserve kidney function in patients at high risk of contrast-induced acute kidney injury (Cl-AKI), the effect in patients at low-moderate risk remains unknown. The preventive effects of RIPC in patients not at high risk of $\mathrm{Cl}-\mathrm{AKI}$ were examined, and biomarkers with anticipated roles in renal protection via RIPC investigated.
\end{abstract}

\begin{abstract}
Methods and Results: Sixty patients who had moderate chronic kidney disease and who underwent angiography were randomly assigned to the control $(n=30)$ or RIPC (intermittent arm ischemia, $n=30)$ group. The baseline characteristics in the 2 groups did not differ significantly. Cl-AKI was evaluated by measuring urinary liver-type fatty acidbinding protein (L-FABP). Biomarkers were measured before and 24 and $48 \mathrm{~h}$ after angiography. Twenty-four hours after angiography, the percent change in urinary L-FABP level in the RIPC group was significantly smaller than in the control group (41.3 \pm 15.6 vs. $159 \pm 34.1 \%, \mathrm{P}=0.003$ ). L-FABP-based Cl-AKI developed in 8 control patients $(26.9 \%)$ vs. only 2 patients in the RIPC group (7.7\%), suggesting that RIPC prevents $\mathrm{Cl}-\mathrm{AKI}$. Factors contributing to $\mathrm{Cl}-\mathrm{AKI}$ were analyzed. Neither high-sensitivity C-reactive protein nor pentraxine-3 level differed significantly between the 2 groups, while the percent change in asymmetrical dimethy larginine (ADMA) level and blood derivatives of reactive oxidative metabolite levels were significantly smaller in the RIPC group.
\end{abstract}

Conclusions: RIPC alleviates $\mathrm{Cl}-\mathrm{AKI}$ in patients at low-moderate risk. This effect might be mediated partly by decreasing oxidative stress and plasma ADMA level. (Circ $J$ 2013; 77: 3037-3044)

Key Words: Contrast-induced acute kidney injury; Coronary angiography; Liver-type fatty acid-binding protein; Remote ischemic preconditioning

$\mathbf{T}$ he use of contrast medium for diagnostic and interventional cardiovascular procedures can cause contrastinduced acute kidney injury (CI-AKI). Risk factors for CI-AKI include chronic kidney disease (CKD), diabetes mellitus (DM), congestive heart failure, intravascular volume depletion, and use of a large volume of contrast medium. ${ }^{1,2}$ Although the mechanism of CI-AKI is multifactorial, the consensus pathogenesis involves combined hypoxic and toxic renal tubular damage with renal endothelial dysfunction and decreased intrarenal microcirculation. Contrast medium-induced hypoxia of the renal medulla leads to the production of renal free radicals via postischemic oxidative stress. ${ }^{3-5}$ Although CI-AKI is associated with prolonged hospitalization and adverse clinical outcome, ${ }^{6}$ the established preventive approach to CI-AKI simply involves identifying patients at risk, minimizing the volume of contrast medium, and providing adequate i.v. volume expansion. ${ }^{7-10}$ Therefore, the development of a novel therapeutic approach for CI-AKI is desirable.

\section{Editorial p 2883}

Although creatinine is widely used, it is a suboptimal marker of renal injury because it does not rapidly reflect the altered glomerular filtration rate (GFR) or degree of tubular injury. ${ }^{11}$ The canonical creatinine-based CI-AKI has a predictable time course, during which creatinine level increases from 24 to $48 \mathrm{~h}$ after contrast medium exposure and peaks within 2-5 days. Moreover, renal function must decrease by more than half before an increase in serum creatinine is detected. The urinary excretion of liver-type fatty acid-binding protein (L-FABP) is a newly emerging biomarker that reflects tubulointerstitial damage, including ischemic and toxic insults, and increases rapidly and peaks within $24 \mathrm{~h}$ after use of contrast medium. ${ }^{12}$ In addition, urinary L-FABP level is increased after contrast medium use in

Received February 1, 2013; revised manuscript received July 4, 2013; accepted July 22, 2013; released online August 29, 2013 Time for primary review: 51 days

Akita University Graduate School of Medicine, Department of Cardiovascular and Respiratory Medicine, Akita, Japan

The authors declare no conflict of interest.

Mailing address: Hiroyuki Watanabe, MD, Department of Cardiovascular and Respiratory Medicine, Akita University Graduate School of

Medicine, 1-1-1 Hondoh, Akita 010-8543, Japan. E-mail: hirow@ doc.med.akita-u.ac.jp

ISSN-1346-9843 doi:10.1253/circj.CJ-13-0171

All rights are reserved to the Japanese Circulation Society. For permissions, please e-mail: cj@j-circ.or.jp 
mild-to-moderate CKD, during which no patient exhibits an increase in creatinine. ${ }^{1}$ Therefore, urinary L-FABP is a more useful marker than creatinine for the early detection of CI-AKI. ${ }^{12-14}$

In 2006, Cheung et al discovered remote ischemic preconditioning (RIPC), in which transient non-lethal ischemia and reperfusion applied to 1 organ protects another organ from a subsequent episode of lethal ischemia and reperfusion injury. ${ }^{15-18}$ Several studies have shown that RIPC can preserve kidney function in patients undergoing elective endovascular or open surgical repair for an abdominal aortic aneurysm and elective coronary artery bypass graft surgery. ${ }^{19-21}$ In addition, RIPC can prevent contrast-medium-induced nephropathy. Er et al showed that RIPC induced by intermittent upper-arm ischemia before an invasive coronary procedure, dramatically reduces the incidence of contrast medium-induced nephropathy $(\mathrm{CIN})^{22}$ in patients at high risk of CI-AKI according to the Mehran risk score. ${ }^{23}$ The preventive effects of RIPC in patients at low-tomoderate risk of CI-AKI, however, remain elusive. In addition, the underlying mechanism responsible for the renal protective effect is unclear. We tested the hypothesis that RIPC attenuates CI-AKI in patients who are not at high risk. Moreover, we investigated biomarkers with anticipated roles in the renal protection resulting from RIPC.

\section{Methods}

\section{Subjects}

Eligible patients who had moderate CKD, who were not in cardiogenic shock and acute renal failure, and who were undergoing angiography were enrolled in this study. Sixty patients scheduled for elective angiographic procedures from February 2011 to October 2012 who had moderate CKD were enrolled in this study. CKD was defined using estimated GFR (eGFR), calculated using the equation of the modification of the diet in renal study, for Japanese individuals as recommended by the Japanese Society of Nephrology as: eGFR $\left(\mathrm{ml} \cdot \mathrm{min}^{-1} \cdot 1.73 \mathrm{~m}^{-2}\right)=194 \times$

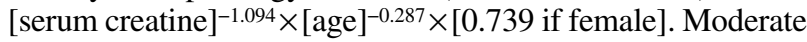
$\mathrm{CKD}$ was defined as eGFR=30-60 $\mathrm{ml} \cdot \mathrm{min}^{-1} \cdot 1.73 \mathrm{~m}^{-2}$. Patients were excluded if the contrast volume used was $<40 \mathrm{ml}$ or $>300 \mathrm{ml}$ after angiographic procedures. The study objectives and protocol were fully explained to the patients and written informed consent was obtained from all patients. The following 4 hospitals participated in this study: Department of Cardiovascular and Respiratory Medicine Akita University Hospital; Division of Cardiovascular Medicine, Honjo Daiich Hospital; Yuri Kumiai General Hospital; and Yamamoto Kumiai General Hospital. The numbers of enrolled patients were 43, 10, 3, and 4 , respectively.

This study was approved by the regional ethics committee in accordance with the standards of the Declaration of Helsinki.

\section{Study Protocol}

This was designed as a prospective, randomized, non-blinded, multicenter study. Sealed envelopes were used to randomly assign treatment with only i.v. volume (control group); or i.v. volume combined with RIPC (RIPC group) at the time of scheduled coronary angiography (CAG) or percutaneous coronary intervention (PCI). Randomization was conducted at the Department of Cardiovascular and Respiratory Medicine, Akita University Hospital, in a single setting. All patients were given $0.9 \%$ isotonic saline i.v. at a rate of at least $1.0 \mathrm{ml} / \mathrm{kg} / \mathrm{h}$ beginning at least $4 \mathrm{~h}$ before angiography, until $12 \mathrm{~h}$ after contrast exposure. All patients were allowed to drink if they were thirsty. RIPC consisted of intermittent upper arm ischemia involving 4 cycles of 5-min inflation of a blood pressure cuff to $200 \mathrm{mmHg}$ and 5-min deflation. The RIPC protocol was applied $2 \mathrm{~h}$ before starting the procedure. CAG and PCI were performed using standard techniques. Interventional devices were selected by the operators. Serious complications did not occur in either group. The low-osmolality contrast medium iopamidol (350 mg iodine/ml; Iopamiron ${ }^{\circledR}$, Bayer Pharmaceutical, Japan) was used. The amount of contrast medium used in each patient was recorded after the procedure. The primary endpoint was the incidence of L-FABP-based CI-AKI as stated in a previous report in which the disease-monitoring L-FABP cut-off level in patients with CKD was $17.4 \mu \mathrm{g} / \mathrm{g} \mathrm{Cr} .{ }^{24} \mathrm{~L}-\mathrm{FABP}-$ based CI-AKI was defined as L-FABP $>17.4 \mu \mathrm{g} / \mathrm{g}$ Cr within $24 \mathrm{~h}$ after use of the contrast medium. If baseline L-FABP was $>17.4 \mu \mathrm{g} / \mathrm{g} \mathrm{Cr}$, L-FABP-based CI-AKI was defined as an increase $>25 \%$ from baseline. Secondary endpoints were the level of high-sensitivity C-reactive protein (hs-CRP), plasma pentraxin 3 (PTX3), the derivatives of reactive oxidative metabolites (D-ROM), and asymmetrical dimethylarginine (ADMA) at $24 \mathrm{~h}$, and serum creatinine, eGFR and cystatin $\mathrm{C}$ at $48 \mathrm{~h}$ after contrast medium exposure. Incidence of creatinine-based CI-AKI was defined as an increase in serum creatinine $>25 \%$ from baseline or an absolute increase $\geq 0.5 \mathrm{mg} / \mathrm{dl}$ within $48 \mathrm{~h}$ after use of contrast medium in accordance with previous reports. ${ }^{2,22,23,25}$

We are planning a study of a continuous response variable from independent controls and experimental subjects with 1 control per experimental subject. In a previous study, ${ }^{1}$ the response within each subject group was normally distributed with standard deviation $39.4 \mu \mathrm{g} / \mathrm{g}$ Cr. If the true mean difference between experimental and control subjects is $30.2 \mu \mathrm{g} / \mathrm{g} \mathrm{Cr}$, then we need to study 28 experimental subjects and 28 control subjects to reject the null hypothesis that the population mean of the experimental and control groups is equal with a probability (power) of 0.8 . The type I error probability associated with this test of the null hypothesis is 0.05 . Therefore, we designed this study as an exploratory effort to assemble the data required to verify this, and determined the sample size considering the operability of this study.

\section{Measurement of Biomarkers}

Urinary L-FABP level was measured on specific ELISA, as described previously. ${ }^{12,26,27}$ Previous studies have shown that urinary L-FABP level increases and peaks at $24 \mathrm{~h}$ after use of contrast medium. ${ }^{1,12}$ Based on these results, we measured urinary L-FABP before RIPC, and at $24 \mathrm{~h}$ and $48 \mathrm{~h}$ after use of contrast medium. Additionally, we measured other biomarkers (hs-CRP, PTX3, D-ROM and ADMA) that may affect urinary L-FABP level before and $24 \mathrm{~h}$ after use of contrast medium. D-ROM was measured using a free radical and antioxidant potential determination device (Free Radical Analytical System 4; Health and Diagnostics, Grosseto, Italy). ${ }^{28}$ The normal range of D-ROM is between 250 and 300 Carr units. ${ }^{29}$ The test was linear up to 500 Carr units and had very good analytical performance, with intra-assay and inter-assay coefficients of variation $<4 \% .{ }^{29,30}$ Serum ADMA level was measured on high-performance liquid chromatography. ${ }^{31}$ In a previous study, serum ADMA level in the normal eGFR group was $0.37 \pm 0.07 \mathrm{nmol} / \mathrm{ml} .^{32}$

In contrast to urinary L-FABP level, the increase in serum creatinine level is detected at $48 \mathrm{~h}$ after use of contrast medium. ${ }^{22,25}$ Contrast medium-induced elevation of cystatin $\mathrm{C}$ is found at $24 \mathrm{~h}$ and persists at least $48 \mathrm{~h} .22,33$ Therefore, we estimated serum creatinine, eGFR and cystatin C, at $48 \mathrm{~h}$ after use of contrast medium.

\section{Statistical Analysis}

Continuous variables are expressed as mean \pm SD or \pm SE. Con- 


\begin{tabular}{|c|c|c|c|c|}
\hline & $\begin{array}{l}\text { All patients } \\
(n=60)\end{array}$ & $\begin{array}{c}\text { Control group } \\
(n=30)\end{array}$ & $\begin{array}{c}\text { RIPC group } \\
(n=30)\end{array}$ & P-value \\
\hline Age (years) & $71.1 \pm 7.8$ & $70.8 \pm 7.6$ & $71.3 \pm 8.1$ & 0.81 \\
\hline Male sex & $43(71.7)$ & $23(76.7)$ & $20(66.7)$ & 0.41 \\
\hline BMI $\left(\mathrm{kg} / \mathrm{m}^{2}\right)$ & $23.6 \pm 3.4$ & $23.6 \pm 2.8$ & $23.7 \pm 3.9$ & 0.86 \\
\hline \multicolumn{5}{|l|}{ Underlying heart disease } \\
\hline Ischemic heart disease & $46(76.7)$ & $24(80.0)$ & 22 (73.3) & 0.55 \\
\hline Peripheral artery disease & 7 (13.5) & $3(11.5)$ & $4(15.4)$ & 0.69 \\
\hline Macrovascular disease & $5(9.6)$ & $3(11.5)$ & $2(7.7)$ & 0.65 \\
\hline Valvular heart disease & $4(7.7)$ & $1(3.8)$ & $3(11.5)$ & 0.31 \\
\hline Pulmonary artery hypertension & $2(3.8)$ & $1(3.8)$ & $1(3.8)$ & 1.00 \\
\hline Cardiomyopathy & $5(9.6)$ & $3(11.5)$ & $2(7.7)$ & 0.65 \\
\hline Bradycardia & 7 (13.5) & $3(11.5)$ & $4(15.4)$ & 0.69 \\
\hline \multicolumn{5}{|l|}{ Blood pressure } \\
\hline Systolic (mmHg) & $120.5 \pm 16.8$ & $119.3 \pm 15.4$ & $120.5 \pm 18.2$ & 0.78 \\
\hline Diastolic (mmHg) & $68.6 \pm 12.4$ & $69.0 \pm 11.8$ & $68.30 \pm 13.3$ & 0.83 \\
\hline Heart rate (beats/min) & $69.8 \pm 9.90$ & $70.8 \pm 10.2$ & $69.1 \pm 9.73$ & 0.50 \\
\hline Contrast medium usage (ml) & $92.4 \pm 36.1$ & $91.8 \pm 39.4$ & $92.9 \pm 33.2$ & 0.90 \\
\hline Total volume of infusion (ml) & $1,402 \pm 160$ & $1,399 \pm 156$ & $1,405 \pm 166$ & 0.89 \\
\hline \multicolumn{5}{|l|}{ Medication } \\
\hline ACEIs/ARBs & $41(68.3)$ & $22(73.3)$ & $19(63.3)$ & 0.50 \\
\hline$\beta$-blockers & $26(43.3)$ & $12(40.0)$ & $14(46.6)$ & 0.63 \\
\hline Diuretics & $20(33.3)$ & $11(36.7)$ & $9(30.0)$ & 0.60 \\
\hline Ca antagonists & $33(55.0)$ & $18(60.0)$ & $15(50.0)$ & 0.49 \\
\hline Statins & $45(75.0)$ & $23(76.7)$ & $22(73.3)$ & 0.83 \\
\hline Diabetes medicines & $20(33.3)$ & $9(30.0)$ & $11(36.7)$ & 0.60 \\
\hline Sulfonylurea & $10(16.7)$ & $6(20.0)$ & $4(13.3)$ & 0.50 \\
\hline \multicolumn{5}{|l|}{ Laboratory data } \\
\hline eGFR $\left(\mathrm{ml} \cdot \mathrm{min}^{-1} \cdot 1.73 \mathrm{~m}^{-2}\right)$ & $48.2 \pm 7.9$ & $48.9 \pm 6.0$ & $47.4 \pm 9.4$ & 0.47 \\
\hline Serum creatinine (mg/dl) & $1.13 \pm 0.24$ & $1.12 \pm 0.17$ & $1.15 \pm 0.29$ & 0.59 \\
\hline Cystatin C (mg/L) & $1.43 \pm 0.46$ & $1.38 \pm 0.28$ & $1.47 \pm 0.59$ & 0.44 \\
\hline Hemoglobin $(\mathrm{g} / \mathrm{dl})$ & $12.5 \pm 1.9$ & $12.3 \pm 1.7$ & $12.7 \pm 2.0$ & 0.47 \\
\hline \multicolumn{5}{|l|}{ Integer Cl-AKI risk score } \\
\hline Mean (Q1-3) & $6(5-9)$ & $6(4-8)$ & $6(4-9)$ & 0.44 \\
\hline$<5$ & $23(38.3)$ & $12(40.0)$ & $11(36.7)$ & 0.79 \\
\hline $6-10$ & $31(51.7)$ & $17(56.7)$ & $14(46.7)$ & 0.45 \\
\hline $11-15$ & $6(10.0)$ & $1(3.3)$ & $5(16.7)$ & 0.09 \\
\hline$>16$ & $0(0.0)$ & $0(0.0)$ & $0(0.0)$ & \\
\hline
\end{tabular}

Data given as mean $\pm \mathrm{SD}, \mathrm{n}(\%)$ or as specified.

$\mathrm{ACEI}$, angiotensin-converting enzyme inhibitor; $\mathrm{ARB}$, angiotensin receptor blocker; BMI, body mass index; $\mathrm{Cl}-\mathrm{AKI}$ contrast-induced acute kidney injury; CKD, chronic kidney disease; eGFR, estimated glomerular filtration rate; RIPC, remote ischemic pre-conditioning.

tinuous, normally distributed data were analyzed using Student's t-test; Mann-Whitney U-test was used for non-normally distributed data. Correlations were evaluated using Pearson's correlation coefficient. $\mathrm{P}<0.05$ was considered to indicate statistical significance. All statistical analysis was performed using SPSS for Windows version 19.0 (SPSS, Chicago, IL, USA). Statistical analysis included all randomized subjects.

\section{Results}

\section{Patient Characteristics}

In total, 60 patients were included in this study and no patient was excluded after randomization. The baseline characteristics of the 60 enrolled CKD patients are summarized in Table 1. The 2 groups did not differ statistically in terms of age, gender, body mass index (BMI), underlying diseases, blood pressure, heart rate, contrast medium use, total volume of saline infusion, ejection fraction, medication, or laboratory data including eGFR, serum creatinine, cystatin $\mathrm{C}$, and hemoglobin levels. In patients with DM, sulfonylurea possibly influences the effects of RIPC by inhibiting ATP-sensitive potassium channels, but there was no significant difference in sulfonylurea use between the 2 groups (control vs. RIPC: $20 \%$ vs. $13 \%, \mathrm{P}=0.50$; Table 1 ). The risk of developing CI-AKI was evaluated using the Mehran risk score. ${ }^{23}$ All subjects were categorized as low-to-moderate risk and there was no significant difference in the mean risk score between 2 groups.

\section{RIPC Reduces Prevalence of CI-AKI}

Twenty-four hours after use of the contrast medium, urinary LFABP level in the control group increased significantly from $7.2 \pm 5.4$ to $14.0 \pm 8.8 \mu \mathrm{g} / \mathrm{g} \mathrm{Cr}(\mathrm{P}<0.001)$, whereas that in the RIPC 

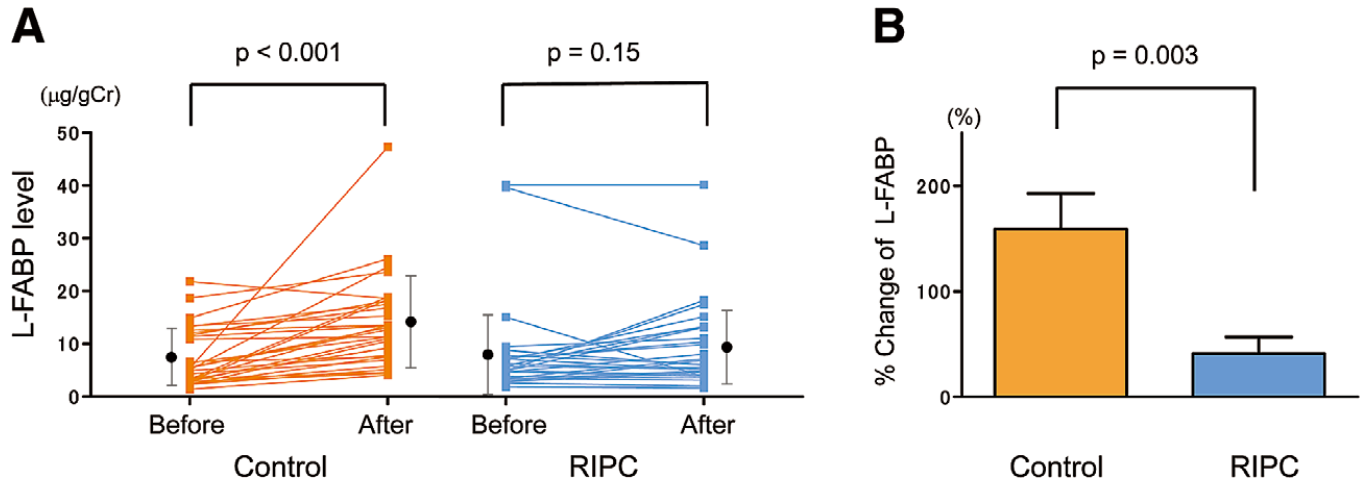

Figure 1. Urinary liver-type fatty acid-binding protein (L-FABP) level before and at $24 \mathrm{~h}$ after use of contrast medium in patients with or without remote ischemic preconditioning (RIPC). (A) Changes in individual data (mean, filled circle; standard deviation, vertical bars); (B) percent change (mean, columns; standard error, vertical bar).

\begin{tabular}{|c|c|c|c|}
\hline & Control & RIPC & P-value \\
\hline \multicolumn{4}{|c|}{ L-FABP $(\mu \mathrm{g} / \mathrm{g} \mathrm{Cr})$} \\
\hline Before & $7.2 \pm 5.4$ & $8.0 \pm 9.1$ & 0.7 \\
\hline $24 \mathrm{~h}$ after & $14.0 \pm 8.8$ & $9.4 \pm 8.3$ & 0.04 \\
\hline $48 \mathrm{~h}$ after & $13.4 \pm 5.7$ & $8.3 \pm 6.5$ & 0.21 \\
\hline \multicolumn{4}{|c|}{ (\%) change of L-FABP } \\
\hline $24 \mathrm{~h}$ after & $159 \pm 34.1$ & $41.3 \pm 15.6$ & 0.003 \\
\hline $48 \mathrm{~h}$ after & $62.4 \pm 26.8$ & $40.0 \pm 17.9$ & 0.48 \\
\hline \multicolumn{4}{|c|}{ Serum creatinine (mg/dl) } \\
\hline Before & $1.12 \pm 0.17$ & $1.15 \pm 0.29$ & 0.59 \\
\hline $48 \mathrm{~h}$ after & $1.19 \pm 0.30$ & $1.16 \pm 0.25$ & 0.7 \\
\hline \multicolumn{4}{|c|}{ eGFR $\left(\mathrm{ml} \cdot \mathrm{min}^{-1} \cdot 1.73 \mathrm{~m}^{-2}\right)$} \\
\hline Before & $48.9 \pm 6.0$ & $47.4 \pm 9.4$ & 0.44 \\
\hline $48 \mathrm{~h}$ after & $47.3 \pm 7.1$ & $49.0 \pm 10.3$ & 0.46 \\
\hline \multicolumn{4}{|c|}{ Cystatin C (mg/L) } \\
\hline Before & $1.38 \pm 0.28$ & $1.47 \pm 0.59$ & 0.44 \\
\hline $48 \mathrm{~h}$ after & $1.46 \pm 0.34$ & $1.45 \pm 0.53$ & 0.81 \\
\hline
\end{tabular}

Data given as mean \pm SD (absolute change) or mean \pm SE (\% change).

L-FABP, urinary liver-type fatty acid-binding protein. Other abbreviations as in Table 1.

\begin{tabular}{|c|c|c|}
\hline & $\begin{array}{c}\text { CI-AKI (-) } \\
\text { n (\%) }\end{array}$ & $\begin{array}{c}\text { Cl-AKI (+) } \\
\text { n (\%) }\end{array}$ \\
\hline Control & $22(73.3)$ & $8(26.9)$ \\
\hline RIPC & 28 (93.3) & $2(7.7)$ \\
\hline
\end{tabular}

Abbreviations as in Tables 1,2 .

group did not change significantly $(8.0 \pm 9.1$ vs. $9.4 \pm 8.3 \mu \mathrm{g} / \mathrm{g} \mathrm{Cr}$, $\mathrm{P}=0.15$; Figure $1 \mathrm{~A}$ ). The percent change in the urinary L$\mathrm{FABP}$ level at $24 \mathrm{~h}$ in the control group was significantly larger than in the RIPC group $(159 \pm 34.1$ vs. $41.3 \pm 15.6 \%, \mathrm{P}=0.003$; Figure 1B). The difference in the mean $\%$ change of L-FABP at $24 \mathrm{~h}$ was 118 , and the $95 \%$ confidence interval $(95 \% \mathrm{CI})$ was 42.7-193. There was no significant difference in \%change of L-FABP level at $48 \mathrm{~h}$ between the control and RIPC group (62.4 \pm 26.8 vs. $40.0 \pm 17.9 \%, \mathrm{P}=0.48$; Table 2 ). When comparing changes in urinary L-FABP level at $24 \mathrm{~h}$, the creatinine, eGFR, and cystatin $\mathrm{C}$ did not change significantly $48 \mathrm{~h}$ after the angiographic procedure in either group (Table 2).

L-FABP-based CI-AKI developed in 10 patients overall: 8 in the control group and 2 in the RIPC group. The difference in the prevalence of CI-AKI in the 2 groups was significant (26.9 vs. $7.7 \%, \mathrm{P}=0.038$; Table 3 ).

\section{RIPC and Biomarkers}

To explore the mechanism responsible for the renal protective effect of RIPC, we examined the inflammatory biomarkers hsCRP and PTX3. As shown in Figure 2, the percent change in hs-CRP (143 \pm 47.5 vs. $104 \pm 36.7 \%, \mathrm{P}=0.53)$ and $\mathrm{PTX} 3(5.1 \pm 6.2$ vs. $8.4 \pm 6.2 \%, \mathrm{P}=0.71$; Figures $2 \mathrm{~A}, \mathrm{~B})$ did not differ significantly between the control and RIPC groups at $24 \mathrm{~h}$ after contrast medium.

The plasma level of D-ROM, an oxidative stress biomarker, was assayed before and $24 \mathrm{~h}$ after angiography. Figure 2C shows that plasma $\mathrm{D}-\mathrm{ROM}$ level increased significantly $(\mathrm{P}=0.01)$ 
A

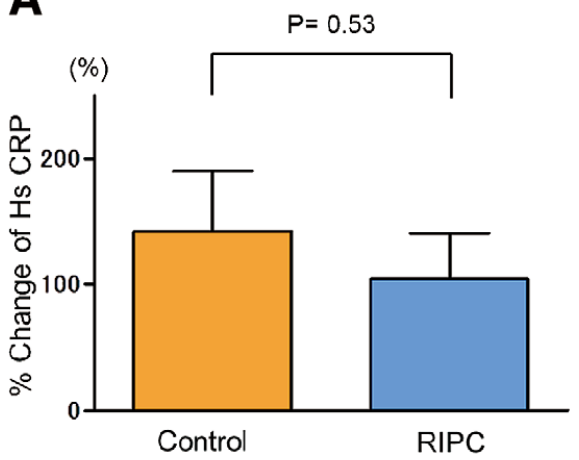

B

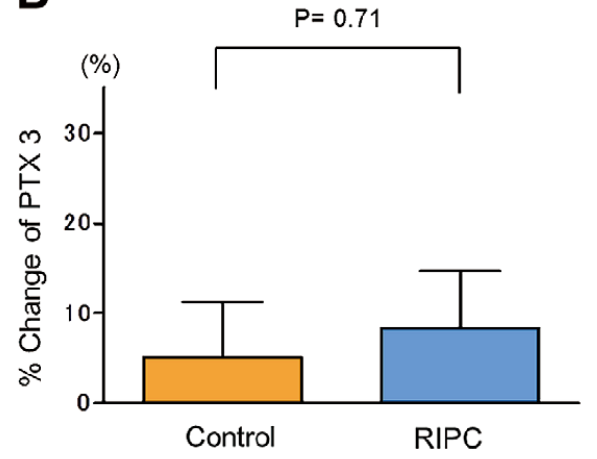

C

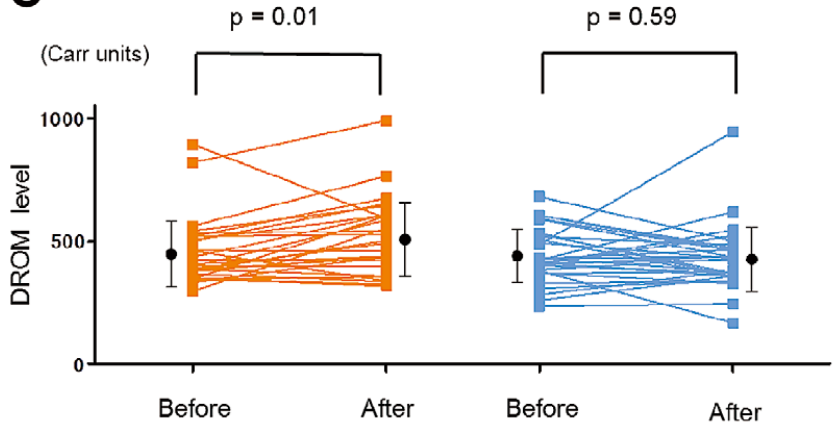

$\mathbf{E}$

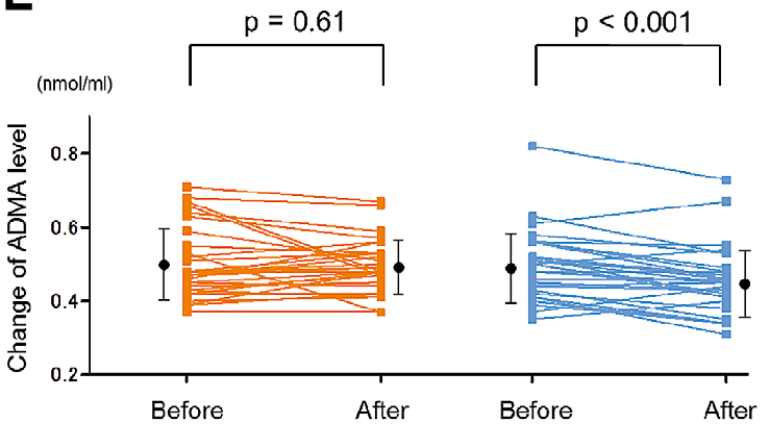

D
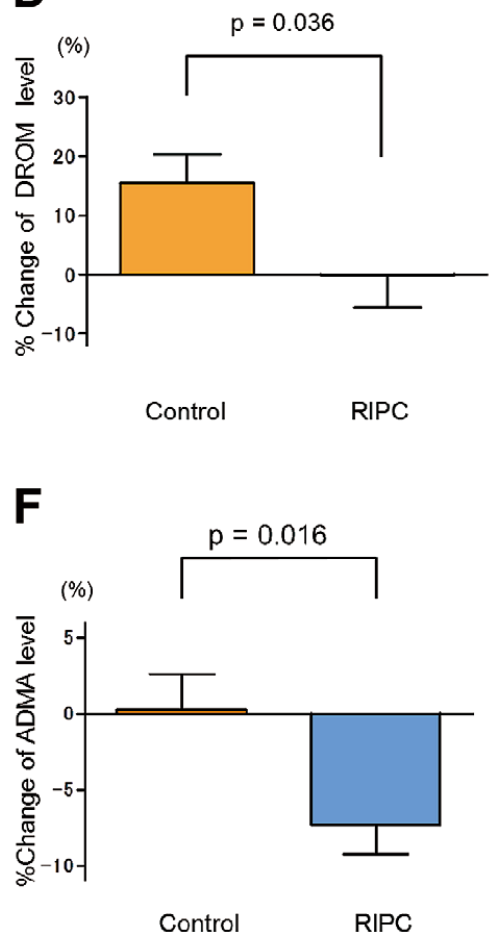

Figure 2. Changes in biomarkers before and at $24 \mathrm{~h}$ after use of contrast medium in patients with or without RIPC. (A,B) Percent changes in inflammation biomarkers. (C) Change and (D) \% change in derivatives of reactive oxidative metabolite (D-ROM) level. (E) Change and (F) \% change in derivatives of asymmetrical dimethylarginine (ADMA) level. (A,B,D,F) Data given as mean (bar) and standard errors (vertical bars). (C,E) Data given as mean (filled circle) and standard deviation (vertical bars). hs-CRP, highsensitivity C-reactive protein; PTX-3, pentraxine-3; RIPC, remote ischemic preconditioning.

from $448 \pm 132$ to $508 \pm 151$ Carr units after use of contrast medium in the control group, while it did not change significantly in the RIPC group ( $441 \pm 109$ vs. $427 \pm 132$ Carr units, $\mathrm{P}=0.59)$. At $24 \mathrm{~h}$, the percent change in plasma D-ROM level was larger in the control group than in the RIPC group (15.5 \pm 4.8 vs. $-0.11 \pm 5.4 \%, \mathrm{P}=0.036$; Figure 2D).

To clarify the involvement of ADMA, an endogenous inhibitor of nitric oxide synthetase (NOS), in RIPC, plasma ADMA level was evaluated before and $24 \mathrm{~h}$ after angiography. In the control group, plasma ADMA level did not change significantly $(0.5 \pm 0.1$ to $0.49 \pm 0.07 \mathrm{nmol} / \mathrm{ml} ; \mathrm{P}=0.61)$ after use of contrast medium, whereas the level decreased significantly in the RIPC group from $0.50 \pm 0.09$ to $0.46 \pm 0.09 \mathrm{nmol} / \mathrm{ml}(\mathrm{P}<0.001$;
Figure 2E). At 24h, the percent change in plasma ADMA level was significantly larger in the RIPC group than in the controls $(-7.33 \pm 1.9$ vs. $0.26 \pm 2.4 \%, \mathrm{P}=0.016$; Figure $2 \mathrm{~F})$.

\section{Change in L-FABP and Change in D-ROM or ADMA}

Figure 3 shows the correlations between change in D-ROM or ADMA and that in L-FABP. Significant correlations were found between D-ROM ( $\mathrm{r}=0.43, \mathrm{P}<0.001$, Figure 3A) or ADMA $(r=0.42, P=0.001$, Figure 3B) and the change in L-FABP.

\section{Discussion}

Although numerous attempts have been made to prevent CI- 


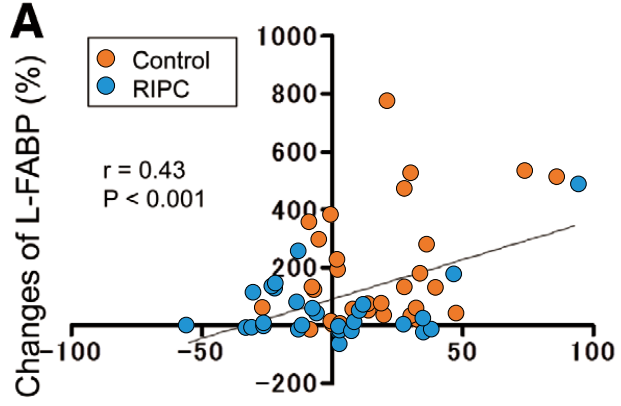

Changes of DROM (\%)

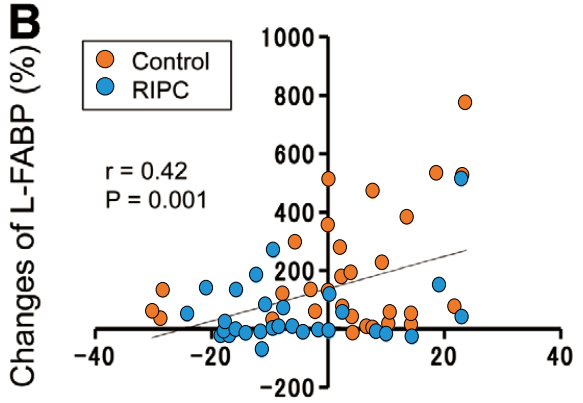

Changes of ADMA (\%)

Figure 3. Correlations between \% change in (A) D-ROM or (B) ADMA and \%change in L-FABP at $24 \mathrm{~h}$ after use of contrast medium. ADMA, asymmetrical dimethylarginine; D-ROM, derivatives of reactive oxidative metabolites; L-FABP, liver-type fatty acid-binding protein; RIPC, remote ischemic preconditioning.

AKI, none is superior to adequate i.v. volume expansion. ${ }^{7-10}$ In recent years, there has been renewed interest in RIPC. This study provides novel insights into the preventative effects of RIPC on CI-AKI. We found that (1) RIPC attenuated the prevalence of L-FABP-based CI-AKI after angiographic procedures in patients with low-to-moderate risk; (2) RIPC inhibited increases in urinary L-FABP, D-ROM, and ADMA level after exposure to contrast medium; and (3) the change in L-FABP level was correlated with the changes in the D-ROM and ADMA levels.

In this study, there was no significant difference in the serum creatinine level between the RIPC and control groups, resulting in the low incidence of canonical CIN, which is defined as an increase in serum creatinine $>25 \%$ from baseline or an absolute increase $\geq 0.5 \mathrm{mg} / \mathrm{dl}$ within $48 \mathrm{~h}$ after use of contrast medium. There were several reasons for the low incidence of CIN in this study. First, the enrolled subjects were at low-to-moderate risk for developing CI-AKI compared with those in previous studies. The prevalence of CIN, however, is $>20 \%$ even in lowmoderate-risk patients. ${ }^{23} \mathrm{We}$ believe the prevention of CI-AKI is important even in patients with low-to-moderate risk. Second, the present study was conducted according to the protocol involving adequate i.v. volume expansion proposed by Stacul et al. ${ }^{34}$ Third, the mean dose of contrast medium was lower in the present study than in previous studies ( 92 vs. $186-190 \mathrm{ml}$ ). ${ }^{1,35}$ For reasons already stated, the incidence of creatinine-based CIN in the present study was lower. Nevertheless, urinary L-FABP level at $24 \mathrm{~h}$ was obviously increased after use of contrast in the control group.

L-FABP expression in the proximal tubules is acutely upregulated under tubular stress due to ischemia or the presence of toxins. ${ }^{36}$ Accordingly, the urinary excretion of L-FABP might precede the occurrence of cell structure damage. ${ }^{13,36}$ As Er et al described, serum creatinine is an inadequate marker of CI-AKI because of its low sensitivity, and cystatin $\mathrm{C}$ is more sensitive than serum creatinine in high-risk patients. ${ }^{22}$ In the present study, however, we found that eGFR, creatinine, and cystatin C did not change significantly $48 \mathrm{~h}$ after the angiographic procedures. Only urinary L-FABP level was altered in response to contrast medium exposure. Similarly, Kato et al reported that urinary LFABP level was increased significantly in the moderate CKD groups compared with before contrast medium, whereas other urinary biomarkers, serum creatinine, and cystatin $\mathrm{C}$ did not increase significantly from baseline. ${ }^{1}$ Furthermore, Nakamura et al showed that urinary L-FABP sensitively and rapidly reflected renal injury compared with creatinine in patients after contrast medium use. This implies that urinary L-FABP is a more useful marker for the early detection of kidney injury than creatinine, even in low-risk CKD patients. ${ }^{12-14,37}$ Conversely, creatinine level may mask latent CI-AKI in the clinical setting. Therefore, we evaluated the effects of RIPC on CI-AKI by measuring L-FABP level. Although the accurate L-FABP cutoff level for determining CI-AKI has not yet been decided, Kamijo et al reported the disease-monitoring L-FABP cut-off level in patients with CKD to be $17.4 \mu \mathrm{g} / \mathrm{g} \mathrm{Cr} .{ }^{24}$ Accordingly, we used the same L-FABP cut-off to determine CI-AKI.

Although the precise mechanisms responsible for CI-AKI are not completely understood, renal ischemic injury and tubular epithelial cell toxicity have been proposed. ${ }^{38}$ The infusion of contrast medium, with the attendant increases in osmotic load and viscosity, elicits hypoxia of the renal medulla and leads to renal free radical production via post-ischemic oxidative stress. ${ }^{3}$ Post-ischemic free radical production might be the mechanism responsible for CI-AKI. ${ }^{3}$ We measured serum D-ROM level as a marker of oxidative stress. After infusing contrast medium, D-ROM significantly increased in the controls compared with the RIPC groups (Figure 2D). Although the underlying mechanisms for the renal-protective effects of RIPC are not fully understood, Tapuria et al have shown that RIPC can reduce oxidative stress via the release of biochemical messengers. ${ }^{39}$ Moreover, the cardioprotective effect of RIPC on reperfusion injury has been shown to be associated with activation of the phosphatidylinositol 3-kinase/Akt (PI3K-Akt) pathway. ${ }^{40}$ The PI3K-Akt pathway reduces oxidative stress by activating nuclear factor-erythroid 2-related factor $2,{ }^{41}$ and induces expression of superoxide dismutase. ${ }^{42}$ These antioxidative effects likely contribute to the prevention of the L-FABP-based CI-AKI.

In rat CI-AKI models, the inhibition of prostaglandin or NO synthesis decreases outer medullary blood flow and aggravates regional hypoxia. ${ }^{43,44}$ Indeed, L-arginine improves the contrast-induced altered renal hemodynamics and renal dysfunction in hypercholesterolemic rats. ${ }^{45}$ These results suggest that amelioration of the altered medullary nitrovasodilation is a possible target in preventing CI-AKI. As shown in Figure 2F, RIPC significantly reduced ADMA level after angiographic procedures compared to the controls. This implies that more 
NO is available in the RIPC group than in the controls. ADMA is an endogenous competitive inhibitor of NOS, and reactive oxygen species are involved in the elevation of ADMA level. ${ }^{46}$ Lin et al reported that application of an antioxidant reversed ADMA accumulation in human endothelial cells. ${ }^{47}$ These observations support our idea that RIPC reduces oxidative stress and results in decrease in ADMA level. Although we could not estimate endothelial function in the present study directly, the improvements in peritubular capillary endothelial function might be involved in the renal protective effect of RIPC.

The pro-inflammatory action of contrast medium in human renal proximal tubular epithelial cells has been postulated..$^{48}$ The anti-inflammatory effect of RIPC, however, remains controversial. Konstantinov et al showed that RIPC suppressed the expression of pro-inflammatory genes in circulating leukocytes in humans. ${ }^{49}$ Conversely, Iliodromitis et al reported that RIPC failed to reduce the increased circulating level of CRP after coronary angioplasty with stenting. ${ }^{50}$ In the present study, there was no significant difference in the hs-CRP and plasma PTX3 levels between before and after use of contrast medium (Figures 2A,B). Further studies are needed to clarify this issue.

The present study has some limitations. First, the study design was non-blinded and the sample size was small. Second, we were unable to observe a sufficient number of events, such as CIN, mortality, and the need for dialysis as endpoints. A much larger study is required to confirm the beneficial effects of RIPC on CI-AKI. Third, we did not examine urinary neutrophil gelatinase-associated lipocalin (NGAL) level, which is also a useful marker of early CI-AKI. Bachorzewska-Gajewska et al reported that the rise in urinary NGAL and L-FABP levels has a similar time course after use of contrast medium. ${ }^{51,52}$ Thus, both markers can be detected before a rise in serum creatinine level. ${ }^{53}$ Furthermore, we did not examine creatinine clearance $(\mathrm{CCr})$, which is also a useful marker of renal function. Examining changes in NGAL and CCr in this type of study is important. To confirm the effects of RIPC on CI-AKI, further studies using NGAL and CCr are needed. Fourth, because the RIPC procedure requires $40 \mathrm{~min}$ from start to finish, applying RIPC immediately before angiography was difficult in this study. Several studies in animal models and humans, however, have shown that the effects of RIPC can persist for at least $24 \mathrm{~h} .{ }^{39}$ Therefore, we applied RIPC approximately $2 \mathrm{~h}$ before CAG (average, $131 \pm 12 \mathrm{~min}$ ). Further study is necessary to determine which RIPC protocol is best for preventing CI-AKI.

\section{Conclusions}

RIPC alleviates CI-AKI in patients at low-moderate risk. This beneficial effect might be mediated partly by decreasing oxidative stress and plasma ADMA level.

\section{Acknowledgments}

The authors thank the hospital staff, Dr. Yasushi Suzuki, Dr. Toru Nakanishi, Dr. Shin Makabe, and Dr. Kunitaka Kimura for their assistance in this study. This study was financially supported in part by Grant-in-Aid for Scientific Research (KAKENHI), Daiichi Sankyo Co, Ltd. and Eisai Co, Ltd. The funders had no role in the study design, data collections and analysis, decision to publish, or preparation of the manuscript. The authors declare no conflict of interest with regard to this study.

\section{References}

1. Kato K, Sato N, Yamamoto T, Iwasaki YK, Tanaka K, Mizuno K. Valuable markers for contrast-induced nephropathy in patients undergoing cardiac catheterization. Circ J 2008; 72: 1499-1505.

2. Naruse H, Ishii J, Hashimoto T, Kawai T, Hattori K, Okumura M, et al. Pre-procedural glucose levels and the risk for contrast-induced acute kidney injury in patients undergoing emergency coronary inter- vention. Circ J 2012; 76: 1848-1855.

3. Brezis M, Rosen S. Hypoxia of the renal medulla: Its implications for disease. N Engl J Med 1995; 332: 647-655.

4. Dauerman HL. In search of an algorithm to prevent acute kidney injury. JACC Cardiovasc Interv 2009; 2: 1125-1127.

5. Heyman SN, Goldfarb M, Carmeli F, Shina A, Rahmilewitz D, Brezis M. Effect of radiocontrast agents on intrarenal nitric oxide (NO) and NO synthase activity. Exp Nephrol 1998; 6: 557-562.

6. Nozue T, Michishita I, Iwaki T, Mizuguchi I, Miura M. Contrast medium volume to estimated glomerular filtration rate ratio as a predictor of contrast-induced nephropathy developing after elective percutaneous coronary intervention. J Cardiol 2009; 54: 214-220.

7. Bartorelli AL, Marenzi G. Contrast-induced nephropathy. J Interv Cardiol 2008; 21: 74-85.

8. Mockel M, Radovic M, Kuhnle Y, Combe V, Waigand J, Schroder S, et al. Acute renal haemodynamic effects of radiocontrast media in patients undergoing left ventricular and coronary angiography. Nephrol Dial Transplant 2008; 23: 1588-1594.

9. Briguori C, Visconti G, Focaccio A, Airoldi F, Valgimigli M, Sangiorgi GM, et al. Renal Insufficiency After Contrast Media Administration Trial II (REMEDIAL II): RenalGuard System in high-risk patients for contrast-induced acute kidney injury. Circulation 2011; 124: 1260 1269.

10. Shoukat S, Gowani SA, Jafferani A, Dhakam SH. Contrast-induced nephropathy in patients undergoing percutaneous coronary intervention. Cardiol Res Pract 2010; 2010: 649164.

11. Waikar SS, Bonventre JV. Creatinine kinetics and the definition of acute kidney injury. J Am Soc Nephrol 2009; 20: 672-679.

12. Nakamura T, Sugaya T, Node K, Ueda Y, Koide H. Urinary excretion of liver-type fatty acid-binding protein in contrast medium-induced nephropathy. Am J Kidney Dis 2006; 47: 439-444.

13. Kamijo A, Kimura K, Sugaya T, Yamanouchi M, Hikawa A, Hirano $\mathrm{N}$, et al. Urinary fatty acid-binding protein as a new clinical marker of the progression of chronic renal disease. J Lab Clin Med 2004; 143: $23-30$.

14. Manabe K, Kamihata H, Motohiro M, Senoo T, Yoshida S, Iwasaka T. Urinary liver-type fatty acid-binding protein level as a predictive biomarker of contrast-induced acute kidney injury. Eur J Clin Invest 2012; 42: 557-563.

15. Cheung MM, Kharbanda RK, Konstantinov IE, Shimizu M, Frndova $\mathrm{H}$, Li J, et al. Randomized controlled trial of the effects of remote ischemic preconditioning on children undergoing cardiac surgery: First clinical application in humans. J Am Coll Cardiol 2006; 47: 2277 2282.

16. Hausenloy DJ, Mwamure PK, Venugopal V, Harris J, Barnard M, Grundy E, et al. Effect of remote ischaemic preconditioning on myocardial injury in patients undergoing coronary artery bypass graft surgery: A randomised controlled trial. Lancet 2007; 370: 575-579.

17. Kharbanda RK, Li J, Konstantinov IE, Cheung MM, White PA, Frndova $\mathrm{H}$, et al. Remote ischaemic preconditioning protects against cardiopulmonary bypass-induced tissue injury: A preclinical study. Heart 2006; 92: 1506-1511.

18. Kharbanda RK, Mortensen UM, White PA, Kristiansen SB, Schmidt MR, Hoschtitzky JA, et al. Transient limb ischemia induces remote ischemic preconditioning in vivo. Circulation 2002; 106: 2881-2883.

19. Ali ZA, Callaghan CJ, Lim E, Ali AA, Nouraei SA, Akthar AM, et al. Remote ischemic preconditioning reduces myocardial and renal injury after elective abdominal aortic aneurysm repair: A randomized controlled trial. Circulation 2007; 116 (Suppl): I98 - I105.

20. Venugopal V, Laing CM, Ludman A, Yellon DM, Hausenloy D. Effect of remote ischemic preconditioning on acute kidney injury in nondiabetic patients undergoing coronary artery bypass graft surgery: A secondary analysis of 2 small randomized trials. Am J Kidney Dis 2010; 56: $1043-1049$.

21. Walsh SR, Boyle JR, Tang TY, Sadat U, Cooper DG, Lapsley M, et al. Remote ischemic preconditioning for renal and cardiac protection during endovascular aneurysm repair: A randomized controlled trial. J Endovasc Ther 2009; 16: 680-689.

22. Er F, Nia AM, Dopp H, Hellmich M, Dahlem KM, Caglayan E, et al. Ischemic preconditioning for prevention of contrast medium-induced nephropathy: Randomized pilot RenPro Trial (Renal Protection Trial). Circulation 2012; 126: 296-303.

23. Mehran R, Aymong ED, Nikolsky E, Lasic Z, Iakovou I, Fahy M, et al. A simple risk score for prediction of contrast-induced nephropathy after percutaneous coronary intervention: Development and initial validation. J Am Coll Cardiol 2004; 44: 1393-1399.

24. Kamijo A, Sugaya T, Hikawa A, Yamanouchi M, Hirata Y, Ishimitsu $\mathrm{T}$, et al. Clinical evaluation of urinary excretion of liver-type fatty acidbinding protein as a marker for the monitoring of chronic kidney disease: A multicenter trial. J Lab Clin Med 2005; 145: 125-133. 
25. Jang JS, Jin HY, Seo JS, Yang TH, Kim DK, Kim TH, et al. Sodium bicarbonate therapy for the prevention of contrast-induced acute kidney injury: A systematic review and meta-analysis. Circ J 2012; 76: 2255-2265

26. Saluja I, Song D, O'Regan MH, Phillis JW. Role of phospholipase A2 in the release of free fatty acids during ischemia-reperfusion in the rat cerebral cortex. Neurosci Lett 1997; 233: 97-100.

27. Kamijo A, Sugaya T, Hikawa A, Okada M, Okumura F, Yamanouchi $\mathrm{M}$, et al. Urinary excretion of fatty acid-binding protein reflects stress overload on the proximal tubules. Am J Pathol 2004; 165: 1243-1255.

28. Nagatomo F, Fujino H, Kondo H, Ishihara A. Oxygen concentrationdependent oxidative stress levels in rats. Oxid Med Cell Longev 2012; 2012: 381763.

29. Trotti R, Carratelli M, Barbieri M. Performance and clinical application of a new, fast method for the detection of hydroperoxides in serum. Panminerva Med 2002; 44: 37-40.

30. Trotti R, Carratelli M, Barbieri M, Micieli G, Bosone D, Rondanelli $\mathrm{M}$, et al. Oxidative stress and a thrombophilic condition in alcoholics without severe liver disease. Haematologica 2001; 86: 85-91.

31. Ueda S, Kato S, Matsuoka H, Kimoto M, Okuda S, Morimatsu M, et al. Regulation of cytokine-induced nitric oxide synthesis by asymmetric dimethylarginine: Role of dimethylarginine dimethylaminohydrolase. Circ Res 2003; 92: 226-233.

32. Fliser D, Kronenberg F, Kielstein JT, Morath C, Bode-Boger SM, Haller $\mathrm{H}$, et al. Asymmetric dimethylarginine and progression of chronic kidney disease: The mild to moderate kidney disease study. $J$ Am Soc Nephrol 2005; 16: 2456-2461.

33. Ribichini F, Gambaro G, Graziani MS, Pighi M, Pesarini G, Pasoli P et al. Comparison of serum creatinine and cystatin $\mathrm{C}$ for early diagnosis of contrast-induced nephropathy after coronary angiography and interventions. Clin Chem 2012; 58: 458-464.

34. Stacul F, Adam A, Becker CR, Davidson C, Lameire N, McCullough PA, et al. Strategies to reduce the risk of contrast-induced nephropathy. Am J Cardiol 2006; 98: 59K-77K.

35. Abe M, Kimura T, Morimoto T, Furukawa Y, Kita T. Incidence of and risk factors for contrast-induced nephropathy after cardiac catheterization in Japanese patients. Circ J 2009; 73: 1518-1522.

36. Kamijo-Ikemori A, Sugaya T, Kimura K. Urinary fatty acid binding protein in renal disease. Clin Chim Acta 2006; 374: 1 -7.

37. Matsui K, Kamijo-Ikemori A, Sugaya T, Yasuda T, Kimura K. Usefulness of urinary biomarkers in early detection of acute kidney injury after cardiac surgery in adults. Circ J 2012; 76: 213-220.

38. Tepel M, Zidek W. N-Acetylcysteine in nephrology; contrast nephropathy and beyond. Curr Opin Nephrol Hypertens 2004; 13: 649-654.

39. Tapuria N, Kumar Y, Habib MM, Abu Amara M, Seifalian AM, Davidson BR. Remote ischemic preconditioning: A novel protective method from ischemia reperfusion injury -- a review. J Surg Res 2008; 150: $304-330$.

40. Hausenloy DJ, Iliodromitis EK, Andreadou I, Papalois A, Gritsopoulos $\mathrm{G}$, Anastasiou-Nana M, et al. Investigating the signal transduction pathways underlying remote ischemic conditioning in the porcine heart. Cardiovasc Drugs Ther 2012; 26: 87-93.

41. Dai G, Vaughn S, Zhang Y, Wang ET, Garcia-Cardena G, Gimbrone MA Jr. Biomechanical forces in atherosclerosis-resistant vascular regions regulate endothelial redox balance via phosphoinositol 3-kinase/ Akt-dependent activation of Nrf2. Circ Res 2007; 101: 723-733.

42. Saxena P, Newman MA, Shehatha JS, Redington AN, Konstantinov IE. Remote ischemic conditioning: Evolution of the concept, mechanisms, and clinical application. J Cardiac Surg 2010; 25: 127-134.

43. Agmon Y, Peleg H, Greenfeld Z, Rosen S, Brezis M. Nitric oxide and prostanoids protect the renal outer medulla from radiocontrast toxicity in the rat. J Clin Invest 1994; 94: 1069-1075.

44. Heyman SN, Brezis M, Epstein FH, Spokes K, Silva P, Rosen S. Early renal medullary hypoxic injury from radiocontrast and indomethacin. Kidney Int 1991; 40: 632-642.

45. Andrade L, Campos SB, Seguro AC. Hypercholesterolemia aggravates radiocontrast nephrotoxicity: Protective role of L-arginine. Kidney Int 1998; 53: 1736-1742.

46. Ueda S, Yamagishi S, Kaida Y, Okuda S. Asymmetric dimethylarginine may be a missing link between cardiovascular disease and chronic kidney disease. Nephrology (Carlton) 2007; 12: 582-590.

47. Lin KY, Ito A, Asagami T, Tsao PS, Adimoolam S, Kimoto M, et al. Impaired nitric oxide synthase pathway in diabetes mellitus: Role of asymmetric dimethylarginine and dimethylarginine dimethylaminohydrolase. Circulation 2002; 106: 987-992.

48. Andreucci M, Lucisano G, Faga T, Bertucci B, Tamburrini O, Pisani A, et al. Differential activation of signaling pathways involved in cell death, survival and inflammation by radiocontrast media in human renal proximal tubular cells. Toxicol Sci 2011; 119: 408-416.

49. Konstantinov IE, Arab S, Kharbanda RK, Li J, Cheung MM, Cherepanov V, et al. The remote ischemic preconditioning stimulus modifies inflammatory gene expression in humans. Physiol Genomics 2004; 19: 143-150.

50. Iliodromitis EK, Kyrzopoulos S, Paraskevaidis IA, Kolocassides KG, Adamopoulos S, Karavolias G, et al. Increased $\mathrm{C}$ reactive protein and cardiac enzyme levels after coronary stent implantation. Is there protection by remote ischaemic preconditioning? Heart 2006; 92: 1821 1826.

51. Bachorzewska-Gajewska H, Poniatowski B, Dobrzycki S. NGAL (neutrophil gelatinase-associated lipocalin) and L-FABP after percutaneous coronary interventions due to unstable angina in patients with normal serum creatinine. Adv Med Sci 2009; 54: 221-224.

52. Malyszko J, Bachorzewska-Gajewska H, Poniatowski B, Malyszko JS, Dobrzycki S. Urinary and serum biomarkers after cardiac catheterization in diabetic patients with stable angina and without severe chronic kidney disease. Ren Fail 2009; 31: 910-919.

53. Waring WS, Moonie A. Earlier recognition of nephrotoxicity using novel biomarkers of acute kidney injury. Clin Toxicol 2011; 49: 720728. 